This item was submitted to Loughborough's Research Repository by the author.

Items in Figshare are protected by copyright, with all rights reserved, unless otherwise indicated.

\title{
Male and female upper body sweat distribution during running measured with technical absorbents
}

PLEASE CITE THE PUBLISHED VERSION

http://dx.doi.org/10.1007/s00421-007-0636-z

PUBLISHER

(c) Springer Verlag

VERSION

AM (Accepted Manuscript)

LICENCE

CC BY-NC-ND 4.0

\section{REPOSITORY RECORD}

Havenith, George, Alison Fogarty, Rebecca Bartlett, Caroline J. Smith, and Vincent Ventenat. 2019. "Male and Female Upper Body Sweat Distribution During Running Measured with Technical Absorbents". figshare. https://hdl.handle.net/2134/9293. 
This item was submitted to Loughborough's Institutional Repository (https://dspace.lboro.ac.uk/) by the author and is made available under the following Creative Commons Licence conditions.

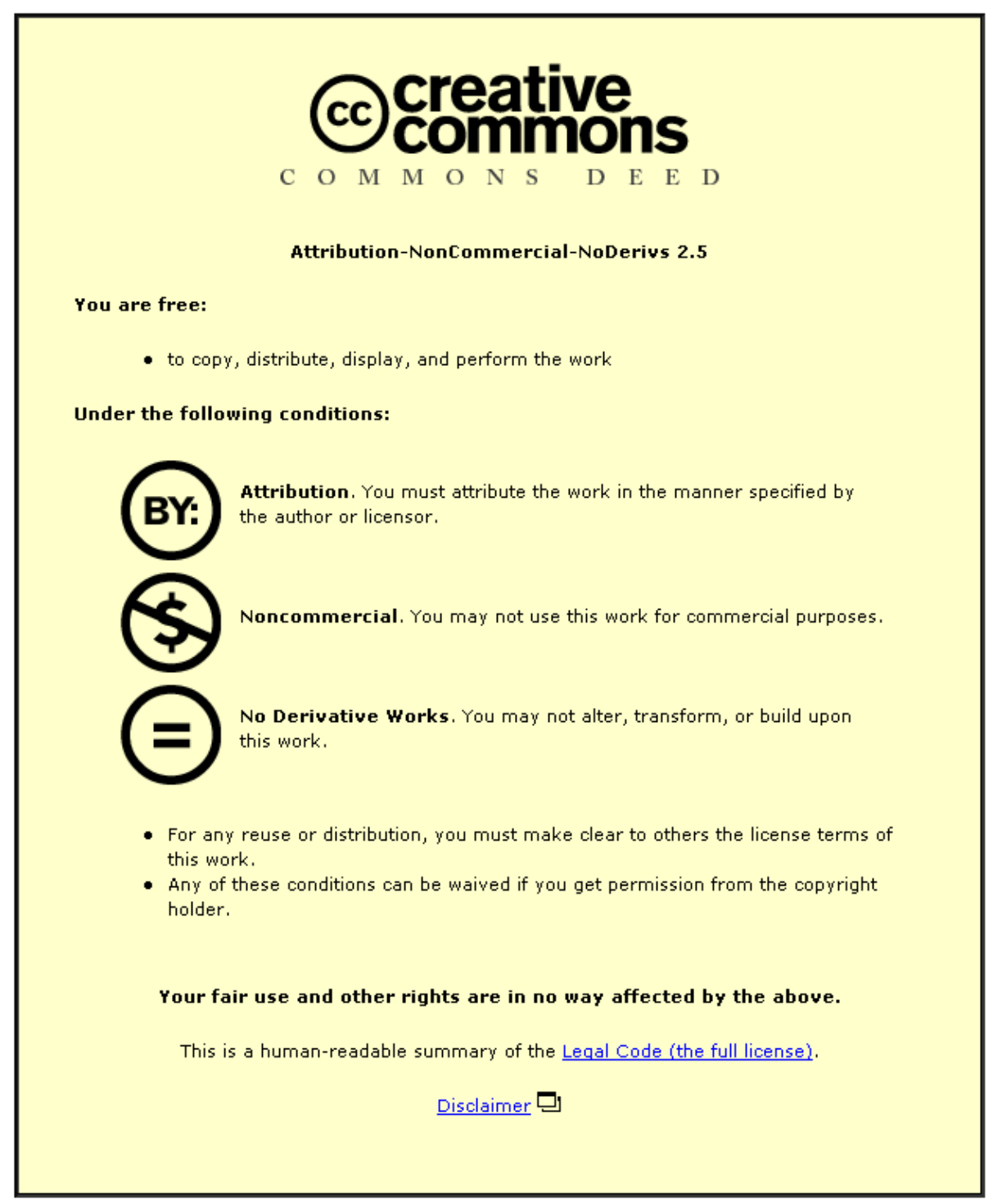

For the full text of this licence, please go to: http://creativecommons.org/licenses/by-nc-nd/2.5/ 


\section{Male and Female Upper Body Sweat Distribution during Running} Measured With Technical Absorbents

\author{
George Havenith $^{1)}$, Alison Fogarty ${ }^{1)}$, Rebecca Bartlett ${ }^{1)}$, Caroline J. Smith ${ }^{1)}$, and Vincent \\ Ventenat ${ }^{2}$. \\ ${ }^{1)}$ Dept. Human Sciences, Loughborough University, UK \\ ${ }^{2)}$ Centre de Recherche DECATHLON, Villeneuve d'Asq - France
}

Contact person: G.Havenith@lboro.ac.uk

Dept Human Sciences

Loughborough University

Ashby Road

Loughborough LE11 3TU

United Kingdom 
1 Abstract

2 Body sweat distribution over the upper body in nine clothed male and female runners of equal

3 fitness while running at $65 \% \dot{\mathrm{V}}_{2 \max }$ and subsequent 15 minute rest in a moderate climate $\left(25^{\circ} \mathrm{C}, 53 \% \mathrm{rh}\right)$ was investigated using technical absorbent materials to collect the sweat produced. No significant difference in whole body mass loss (male 474 SD 80; female 420 SD $114 \mathrm{~g} . \mathrm{m}^{-2} \cdot \mathrm{h}^{-1}$ ) nor surface weighted average of all tested zones for exercise (male 636 SD 165; female 565 SD 222 g.m $\mathrm{m}^{-2} \cdot \mathrm{h}^{-1}$ ) nor rest (male 159 SD 46; female 212 SD 75 g.m $\mathrm{m}^{-2} \cdot \mathrm{h}^{-1}$ ) were observed. Local sweat rate (LSR) ranges were large and overlapped substantially in most areas. Males showed higher LSR for the mid-front $(\mathrm{p}<0.05)$, sides $(\mathrm{p}<0.05)$, and mid lateral back $(\mathrm{p}<0.01)$ compare to females. Both sexes showed similar sweat distribution patterns over the upper body with some exceptions. Males showed higher relative (local to overall) sweat rates than females for the mid lateral back $(\mathrm{p}<0.001)$, while it was lower for the upper arm $(\mathrm{p}<0.001)$, lateral lower back $(\mathrm{p}<0.05)$, and upper central back $(\mathrm{p}<0.05)$. Sweating in both sexes was highest along the spine, and higher on the back as a whole than the chest as a whole. Upper arm sweat rate was lowest. Males showed a higher ratio of highest to lowest LSR (4.4 versus 2.8; $\mathrm{p}<0.05$ ). The present study has provided more detailed information, based on more subjects, on upper body sweat distribution than previously available, which can be used in clothing design, thermo-physiological modelling, and thermal manikin design.

Abstract word count 250

Keywords: sweating, sex, gender, exercise, regional, clothing 


\section{Introduction}

The study of regional sweat rates has gained renewed interest for developments in sportswear and outdoor clothing, where with advancing textile technology a more regionalised design is now possible. Also the development of more sophisticated sweating thermal manikins, which are now able to simulate sweat production in different body zones, require such data, as do developers of mathematical models of human thermoregulation, where they want to include regional differences. The present study was initiated with these applications in mind, and will attempt to chart regional sweat rate on the upper body, covering the whole torso skin area and the upper arms. In addition, attention will be given on how these sweat rates are different between a group of males and females and how the sex of the participants affects the sweat distribution.

Differences in whole body sweat rates between sexes are well investigated, with most research indicating lower overall sweat rates in females linked to a higher core and skin temperature setpoint for sweating in the females (Bar-Or 1998, Bittel and Henane 1975, Cunningham et al. 1978, Fox et al. 1969, Haslag and Hertzman 1965, Wyndham 1965). Others, studying males and females at equal relative workloads, or of equal fitness levels, observed similar sweat rates in absolute values or when expressed as \% of the maximal sweat rate for the individual (Davies 1979, Havenith et al. 1990, 1995) showing the importance of fitness above that of sex for thermoregulatory responses (Havenith et al. 2001).

Regional sweat rates in males versus females received less attention, with most studies on regional sweat distribution focussing on males, studying sweat regulation (Nadel et al. 1971), effects of fitness (Inoue et al. 1999), and ageing (Inoue et al. 1991). Only one study reported actual data for regional female and male sweat rates (Inoue et al. 2005), be it in passive heating without exercise. Several studies looked at heat activated sweat gland (HASG) distribution over the body. Kondo et al. (1998) and Inoue et al. (1991) observed similar HASG densities for back, forearm and thigh, though sweat production was lower on the extremities. Comparing males versus females it was observed that females had a higher density of HASG than males (Bar-Or et al. 1968, Kenney 1985, Kawahata 1960), though as mentioned earlier sweat output was less indicating the production of more but smaller sweat drops in females. The latter may affect evaporative efficiency (Bar-Or 1998). Total numbers of HASG for males are supposedly higher than for females (Kenney et al. 1985) though Knip 
1 (1969) calculated equal numbers on the basis of the lower surface area for females combined 2 with the higher HASG density.

3 Most of the mentioned studies of regional sweat rate distribution used 3 to 5 ventilated sweat capsules per experiment with typically a single capsule per body part. As these capsules each cover only around 2 to $9 \mathrm{~cm}^{2}$, this implies that only a small sample of the whole body is taken and it remains unclear how representative these samples are for the whole area on which they are placed (typically chest, back, arm, thigh) or for overall body sweat rate (Cotter, 1995). Fewer studies have attempted measuring the whole skin in the area studied, rather than just a small zone. Very recently several attempts were made to get data with more extensive skin coverage of body segments: Studies with increased numbers of capsules were performed on the feet (5 capsules, Taylor et al. 2006) and head (10 capsules, Machado-Moreira et al, 2007 ${ }^{\mathrm{b}}$ ), while Fogarty et al. (2007) studied regional foot sweat rates of people carrying a back-pack, using absorbents applied for short periods to the whole foot skin (8 separate zones) while the participants were walking and Smith et al. (2007) did the same for squash players, covering their whole arm and hand skin (11 zones). To our knowledge, few such detailed data were available on the upper body, and only recently this has become a topic of detailed study (Havenith et al. 2007 using absorbents, Machado-Moreira et al, 2007 ${ }^{\mathrm{a}}$ using 12 capsules on torso). The torso and upper arm will therefore be the focus of the present study.

With the application of the data in sports clothing design in mind, the situation of fit runners performing a one hour run in normal running gear in a moderate environment was chosen as test protocol. The goal of the experiment was to measure a large number of locations in one test, sampling the whole skin in these areas. Most available techniques for quantitative sweat sampling would be too complex and time consuming, making simultaneous measurement of many zones impossible. Based on experience of the authors in earlier studies (Inoue et al. 1999), the ventilated capsule method was believed to be too difficult to apply reliably in large numbers covering sufficient upper body areas simultaneously during running; would be difficult to apply airtight in the concave area of the spine; and would interfere with arm movement at the side. Hence it was decided to use an absorbent based method for use in this study. 


\section{Methods}

Nine females and nine males volunteered to participate in this study. All were fit and regular runners. After explanation of the study methods and goals they all signed an informed consent. The study was approved by the Loughborough University ethics committee. Participants visited the laboratory twice. Once for familiarisation with the equipment, determination of fitness and running speed and to have their anthropometric torso measures taken, and a second time for the actual test. A number of torso and arm dimensions were taken, which allowed the sweat absorbent patches to be individually sized, and ensured that the same areas were covered on each participant, scaled to their body size (see electronic supplementary material, ESM 1). Sampling areas were selected based on discussion with clothing designers. Aerobic fitness levels, expressed as $\dot{V}_{O_{\max }}$ were deduced from the relation between measured heart rate and workload (calculated from treadmill speed and angle; Epstein et al. 1987) on the treadmill taken at submaximal levels in the absence of any heat stress using the Åstrand-Ryhming methodology (American College of Sports Medicine, 1995).

Before each trial, 3 sets of absorbent material patches (Technical Absorbents Ltd, Grimsby, UK) were cut to size, individually placed in an airtight zip-lock bag and weighed. After the trial these were weighed again and based on the weight change and the surface area of the patch sweat rate was calculated.

\section{Running trial protocol:}

All trials were completed in a climate controlled laboratory where the average temperature and relative humidity were $25.5^{\circ} \mathrm{C}$ (SD 0.6) and 53\% (SD 5) respectively. Participants were instructed against the use of alcohol the day before the test, and ingestion of food and caffeine 2 hours before the trial. They also received instructions on control of their hydration level with the goal of maintaining euhydration. Upon arrival, participants donned a pair of testing shorts, and their weight was taken. They then donned their own shoes and socks, females their own sports bra, and a T-shirt (Quechua Novadry; Decathlon, France) provided by the laboratory. Subsequently, their resting heart rate (Polar Electro Oy, Kempele, Finland) and an auditory canal temperature (Thermoscan, Braun GmbH, Kronberg, Germany) and oral temperatures were recorded. Throughout the trial, the participant's heart rate was recorded at 15 -second intervals. The running was completed on a treadmill (h/p/cosmos mercury 4.0, h/p/cosmos sports \& medical gmbh, Nussdorf-Traunstein, Germany), with three $50 \mathrm{~cm}$ diameter fans (JS 
1 Humidifiers plc, Littlehampton, UK), arranged in a vertical line to provide an equal distribution over the height of the body, set at a wind speed of $2.0 \mathrm{~m} \cdot \mathrm{sec}^{-1}$ to simulate wind cooling. Wind speed relative to the participant was arbitrarily set lower than running speed to accommodate for situations where actual wind is present but does not come from the front (for detailed consideration see ISO 9920, 2007). Participants were required to run for 60 minutes (Fig. 1). The first 5 minutes of the trial were used to warm-up and to determine the running pace. The treadmill speed was determined through consultation with the participant to ensure they could maintain the speed throughout the 60-min trial and have an average heart rate between 150 and 160 beats. $\mathrm{min}^{-1}$, aiming for a relative work rate of $65 \%$ of $\dot{V} \mathrm{O}_{2 \max }$. Following the 60-minute run, data collection continued for another 15 minutes. During this time, the participant sat on a stool placed on the treadmill in the $2.0 \mathrm{~m} . \mathrm{sec}^{-1}$ wind. Throughout the trial, participants were able to drink water at ambient temperature freely and were encouraged to remain euhydrated. The water consumed was recorded.

\section{Sweat sampling periods}

There were three sweat sampling periods during the trial. During the first two sampling periods, the participant stepped off the treadmill; their T-shirt (and sports bra) was removed; and sweat was wiped off with a towel. For determination of regional skin temperatures, Infra-red thermal image photographs (Thermacam B2, FLIR Systems Ltd., West Malling, Kent, United Kingdom) were taken of their dried upper body (front and back). Pictures were later analysed (Thermacam Reporter Pro, FLIR Systems Ltd., West Malling, Kent, United Kingdom) for local and mean upper body skin temperatures (of the sweat collection areas), of which an example is given in ESM 2. Next, sweat patches, which were pre-configured on plastic sheeting matching the participant's upper body dimensions were applied to the skin. In the females a fresh sports bra with patches inside was put on before applying the other patches. A timer was started at this point to record application time. Participants then put on a stretchy T-shirt to ensure the patches were intimately touching the skin with a low, uniform pressure. This whole process was generally completed in less than 3 minutes. The participant then continued running on the treadmill until the end of the 5-minute sampling period. As the sampling period ended, the participant stepped off the treadmill; the T-shirt was removed, followed by the plastic sheeting, sports bra and all patches, at which time the timer was stopped. They then put the original sports bra and T-shirt back on and started running again. The final sampling period was during the cool down period at the end of the trial. Preparation 
1 for the sampling was started after 30 minutes running, after 45 minutes running and 8 minutes

2 after the end of the run, which due to the preparation time means that actual sampling took place at minutes 33-38, 48-53 and 70-75.

In total 18 different areas were defined for which sweating was collected. Their location is best shown in Fig. 2. Following each sample period, the absorbent patches were immediately removed from the plastic sheeting and sports bra and placed back in their respective sealed plastic bags. Once the trial had finished the patches from all three sampling periods were then weighed (Sartorius 1213MP, resolution 0.01g; Sartorius AG, Goettingen, Germany) and sweat production was calculated as: SR (in g.m $\left.^{-2} \cdot \mathrm{h}^{-1}\right)=\left(60\right.$ [minutes.hour ${ }^{-1}$ ] $\times$ weight change [grams])*(application time [minutes] $\times$ surface area of patch $\left.\left[\mathrm{m}^{2}\right]\right)^{-1}$. At start and end of the test, participants were weighed (Sartorius KCC150/ID7, resolution 1g, Sartorius AG, Goettingen, Germany). Whole body sweat loss was then calculated from the before and after test body weights, corrected for metabolic and respiratory mass losses, and the water consumed. A final auditory canal and oral temperature were also recorded.

In the investigated region, all skin was covered by absorbent during the test period, to assure collection of all sweat and to avoid sweat migrating between areas. Additional patches were placed in the neck region to collect any sweat running down from the head and neck which could contaminate the measurement. These were then discarded.

Apart from calculating sweat production for each patch, also a normalised sweat rate was calculated for each patch for each individual. For this purpose, all the individual zones' absolute sweat rates were divided by the surface area weighted average of all tested zones (mean upper body sweat rate) for the specific person.

\section{Statistics}

Statistical analysis was performed using 'SYSTAT' (SYSTAT Inc, Version 11). The experiment was treated as a repeated measures design (the different zones on the same person) with sex as a between subjects factor, allowing the use of repeated measures ANOVA with SEX, ZONE, and the SEX-ZONE interaction as factors. Strictly speaking, the different zones are not repeated measures as such, as it is not the exact same variable that is measured. However, they are also not independent from each other as measured on the same subjects and on balance it was decided that the repeated measures design would best reflect the situation. 
1 Post hoc testing related to comparisons of zones within the person, and comparisons of zones between sexes.

With 18 zones being compared between sexes, and over 50 comparisons between zones within subjects, multiple post-hoc comparisons are made with the risk of inflating type I error. Based on literature discussions on this issue (Perneger 1998, Bender and Lange 1998) it was decided that a Bonferroni or Holm-Bonferroni correction would be overly conservative (pushing the limit p-value for significance to 0.003 for SEX alone and below 0.001 for within subject comparisons) for the present type of exploratory study, especially given the low number of subjects, and would dramatically inflate type II error. As suggested by Perneger (1998) and Bender and Lange (1998), it was decided to provide uncorrected p-values and bring to the reader's attention that these should be interpreted with multiple comparisons in mind. Significance of comparisons which include the Bonferroni correction will also be reported.

As many publications have shown that sweat production data for a population can be skewed, often with outliers present, medians were used for graphical presentations in this study.

\section{Results}

The characteristics of the participants are presented in Table 1. Females were smaller and lighter $(\mathrm{p}<0.05)$, but their fitness levels did not differ significantly from the male group ( $>0.05$ ). Heart rates, treadmill speed and total body sweat loss also did not differ between the sexes ( $p>0.05$ ), though on average males sweated $13 \%$ more.

Male and female sweating did not differ between the first and second sample ( $>>0.05)$ but ten minutes after exercise stopped (time $=70$ minutes), sweat rates had come down substantially from averages of 636 and $565 \mathrm{~g} \cdot \mathrm{m}^{-2} \cdot \mathrm{h}^{-1}$ during exercise to 159 and $212 \mathrm{~g} \cdot \mathrm{m}^{-2} \cdot \mathrm{h}^{-1}$ respectively for males and females $(\mathrm{p}<0.001)$. This represented a reduction to $25 \%$ of the exercise sweat rate for males, but only to $41 \%$ in the females. Body core temperatures increased by $1.3^{\circ} \mathrm{C}$ for the males and $1.2^{\circ} \mathrm{C}$ for the females (male-female $\mathrm{p}>0.05$ ).. Male mean skin temperature of the sampled area remained rather constant around $34.1^{\circ} \mathrm{C}$, while female skin temperature started higher at $35.0^{\circ} \mathrm{C}$ and then dropped to $33.4^{\circ} \mathrm{C}$ during the run (male-female $\mathrm{p}>0.05$ ). Dehydration during the test averaged to $0.9 \%$ of body weight indicating that hydration levels were well maintained. 
1 Data on the sweat rates recorded by the sweat patches averaged over the two exercise sample periods are presented in Table 2, and the medians graphically shown in Fig. 2 (see also ESM3). The resting data are presented in ESM-4. For the graphical presentation left and right symmetrical zones were averaged (as there was no effect of left versus right or of handedness), and numbers were rounded to the nearest 10 grams. The absolute sweat rates showed a large variation for the different zones within each sex group, and different zone sweat rate ranges overlapped substantially. Nevertheless, significant differences in sweating were observed. Overall, the effect of ZONE (within subjects) was highly significant $(p<0.0005)$, while the overall effect of SEX was not significant. There was a significant interaction of ZONE and SEX ( $\mathrm{p}<0.005)$, indicating that certain zones sweated more in males while others sweated more in females. The results for post hoc tests on this are presented in Table 2.

Between zone comparisons indicated the relatively high sweat rate on the central back (spine), being significantly higher than all other zones, while the lower front, arm, side and shoulder were significantly lower than most other zones. Comparing males and females in terms of absolute sweat rate values, higher zone sweat rates were observed for males for the mid-front $(\mathrm{p}<0.05)$, the sides $(\mathrm{p}<0.05)$, and the mid lateral back $(\mathrm{p}<0.01)$.

In order to get an even clearer picture of differences in distribution between males and females of upper body sweat rate, sweat rates of both males and females were normalised using the surface area weighted average of all tested zones of the individual as reference. The results are shown in Fig. 3, where numbers lower than 1 indicate sweat rates below average, while those above 1 indicate above average sweat rates. From Fig. 3 it is immediately evident that for both sexes the mid central back shows the highest sweat rate; that the back as a whole sweats substantially more than the chest as a whole; and the peripheral parts, the upper arms, show the lowest sweating. Statistical results for the comparison of different zones are presented in Table 3, where a number of the back zones were lumped to reduce the number of required comparisons.

In terms of male-female comparison, males showed higher relative sweat rates than females for the mid lateral back $(\mathrm{p}<0.001)$ and sides $(\mathrm{p}<0.05)$, while it was lower for the upper arm ( $p<0.001)$, the lateral lower back $(\mathrm{p}<0.05)$, and the upper central back $(\mathrm{p}<0.05)$. To look at the range of sweating values in terms of distribution, the ratio of the highest sweating areas 
1 (central back) to the lowest area (upper arm) was calculated. This ratio was higher in males than in females $(\mathrm{p}<0.05)$ showing a bigger sweat ratio between central and peripheral zones in the males. Mean sample area sweat rate for the upper body correlated significantly with overall body sweat loss: for males $r=0.83, p<0.01$, for females $r=0.88, p<0.01$ and combined $\mathrm{r}=0.87, \mathrm{p}<0.001$.

\section{Discussion}

In the current experiment an attempt was made to gather upper body sweating data specifically for the situation of a one hour (approximately $10 \mathrm{~km}$ ) run in clothed, equally fit male and female runners in a moderate climate. Sweating was stable over the two exercise sampling periods, but dropped quickly after the exercise stopped, with the male's sweat rates dropping faster than the female's. Results showed very large variation in individual results, consistent with literature data (Kuno 1956; Weiner 1945; Sodeman and Burch 1943; Cotter et al. 1995). As shown in table 2, sweat rate ranges for individual zones were as large as $688 \mathrm{~g} \cdot \mathrm{m}^{-2} \cdot \mathrm{h}^{-1}$ for the females and $536 \mathrm{~g} \cdot \mathrm{m}^{-2} \cdot \mathrm{h}^{-1}$ for the males. This was caused by some 'outliers' especially to the high side in the females as indicated by the high means compared to medians. Despite the large variation the experiment nevertheless produced a clear picture of sweat distribution as shown in Fig. 3, with significant differences in sweat production for different zones within subjects: the back as a whole sweated most with peak values along the spine, followed by the chest as a whole, and upper arm the lowest. While overall males and females did not show a significant difference, there was a clear interaction of sex with sweat distribution over the different zones. The lower sweat rate for females compared to males in the mid lateral back together with the higher relative sweat rate in the upper chest is perhaps the most striking. The upper chest area in the females was covered by a bra, which may have pushed up sweat rate, though skin temperatures were not significantly higher in this area apart from the small area between the breasts. The lower sweat in the mid lateral back was the area just below the brastrap, where more pressure is present, though it is unclear whether this could have had an effect. Here too no significant temperature deviation from other sampled regions was observed. Another important difference between sexes was the significant difference in ratio high-to-low sweat rates, i.e. central back to upper arm ratio. This is significantly higher in males, showing the larger range between sweat zones in males. For both sexes, zones along the central line (sternal and spinal) show higher sweat rates than more lateral zones, which agrees with findings by Hertzman (1957) though not observed by Cotter et al. (1995). 
Due to differences in heat and exercise protocol, it is difficult to compare the present absolute data with literature. Cotter et al. (1995) exercised their male only subjects at a lower rate (40\% $\left.\dot{\mathrm{V}}_{2 \max }\right)$ but a higher temperature $\left(37^{\circ} \mathrm{C}\right)$, and observed a very high mean steady state sweat rate (1194 g.m $\mathrm{m}^{-2} \cdot \mathrm{h}^{-1}$ ) by their capsules (not surface area weighted), while the observed whole body sweat loss of $816 \mathrm{~g} . \mathrm{m}^{-2} \cdot \mathrm{h}^{-1}$ is much closer to that observed here. Their local sweat to mean sweat ratios show a similar relative distribution as the present data, with similar range, though arm and scapula seem to be shifted to higher ratios [front torso $(0.90 \mathrm{v} 0.93$ in present test), scapula (1.4 v 1.2), medial lower back (0.96 $v 1.0)$ and upper arm (0.8 $v 0.4)$ ]. Weiner (1945), for the trunk, found a ratio of upper chest, lower chest, abdomen, scapula and lumbar of 1.1, 1.1, .87, 0.6 and $0.86(\mathrm{n}=3)$. These ratios are lower for the back than the front, which is different from both the present as well as Cotter et al.'s (1995) data. Finally Nadel et al. (1971), using ventilated capsules, found ratios for chest, abdomen, scapula, and upper arm of 1.2, 0.83, 1.27, and 0.56, which follows a similar pattern to the present data, but higher sweating ratios on the chest. The only quantitative data $\left(10 \mathrm{~cm}^{2}\right.$ capsules) published on females compared to males (passive heating, Inoue et al. 2005) with slightly higher (nonsignificant) fitness levels in the males shows higher sweating in males for chest, back and forearm and equal rates on the thigh compared to females. Chest and back rates were very similar however, with chest rates marginally higher than back in males and reverse in females.

The observed distributions, with a higher sweat rate on the back versus the chest do not match the evaporative heat transfer potential of front versus back. Due to airflow patterns across the chest while running, with the back being the lee-side, the evaporative (and dry) heat transfer coefficient will be higher at the front than at the back making it easier for sweat to evaporate from the front. It therefore seems to be inefficient to produce more sweat at the back than at the front as this is bound to lead to more waste by drippage. A possible explanation would have been that due to the wind chest temperatures were lower than the back's and the local skin temperature effect on sweating would cause the chest to sweat less. However, skin temperatures on chest and back were very close (male difference $<0.4^{\circ} \mathrm{C}$, female $<0.3^{\circ} \mathrm{C}$ ) and not significantly different, so this explanation is unlikely. It may be speculated that this observation is a remnant of evolutionary developments before man became bipedal (B. Bogin, personal communication). In a quadruped creature, the chest is more protected from air movement by arms and legs while the back is more exposed and parallel to air movement. 
1 Thus in quadrupeds, evaporative heat transfer coefficients of the back will be relatively higher compared to bipeds, with the reverse for the chest. Hence higher back sweating would be more effective and give a greater evaporative cooling potential in quadrupeds. As it is generally assumed that eccrine glands increased in number and importance during the transition from quadruped to biped (Jablonski 2006, Folk et al. 1991) the question would remain why the distribution of sweating would not have adapted in the same context.

It is difficult to find a physiological explanation for the strong regional variation of sweat rates, especially the torso versus periphery difference that is observed here and in the literature. When active, arms and legs move and thus will have higher evaporative heat transfer coefficients. This should make it more effective to sweat there as more sweat would evaporate. On the other hand, when slightly cool, the body cuts blood flow to extremities' skin dramatically, which reduces skin temperature and thus also the wet skin's saturated vapour pressure. This reduces evaporative potential on the extremities. However while active and while requiring cooling it is unlikely that this takes place, except perhaps for the transition area between being warm and cool where sweating and reduction in vasodilation may temporarily go together. The authors have observed situations of exercise in cool environments with sweating present, where skin temperatures in extremities are substantially reduced (Havenith, unpublished data).

A number of studies are available in the literature on regional sweat distribution. Some have looked at sweat gland distribution (Kuno 1956; Randall 1946; Kenney et al. 1988), while others studied actual sweat production. Most of the latter studies, given the labour intensive nature of the data collection, have worked with few subjects. Weiner (1945), Hertzman (1957), Cotter et al. (1995) had 3, 5 and 6 men respectively, while the only study measuring regional sweating in males and females in a large number of areas by Kuno (1956) produced data on just four males and four females, all Japanese. Unfortunately the latter study only presents the data of both sexes lumped together. Only Inoue et al. (2005) have data on 4 capsule locations in both sexes, however that was with passive heating. To get a more representative comparison for exercise, the number of participants for the present study was raised to 9 in each sex group.

Technique comparison 
1 The technique used in the present study, absorbents, had been used before, but to our knowledge this was the first study to use new Technical Absorbents and also the first using these over larger body areas simultaneously. Most studies in literature followed different methodologies for sweat collection with most of the quantitative studies using various types of capsules to collect sweat. This implies that only a small fraction of the upper body surface was included in the sampling. Sodeman and Burch (1943) tested resting subjects collecting sweat from 17 areas (4 simultaneously), but only from $10 \mathrm{~cm}^{2}$ per segment, and only $30 \mathrm{~cm}^{2}$ total from the torso, equivalent to about $0.5 \%$ of the torso skin area. Weiner (1945) recognised this as an issue and increased the samples per area, bringing the sampled area of the torso up to 6\%. Hertzman (1957) sampled 20 locations on the front of the body only, of which 9 were at the chest, covering less that $4 \%$. Even extensive work by Cotter et al (1995) using repeated trials to measure a total of 11 locations over the body, covered only $0.2 \%$ of the torso surface with 5 capsules of $2.19 \mathrm{~cm}^{2}$. With such small coverage percentages, the question remains open whether the capsule data are representative for the whole body part studied or for whole body sweat rate. For example, Cotter et al. (1995) did not observe a correlation of his local sweat rates with overall body sweat rate. In order to get higher skin coverage of the measurement and thus being able to represent all the skin areas studied, the present study used absorbent patches that covered the whole torso and upper arm area simultaneously during the sample periods. In the present study a highly significant correlation $(\mathrm{p}<0.001)$ was found between the data from the absorbent samples and overall body sweat loss calculated from drinking corrected mass loss, even though the latter also included a 15 minute resting period.

In comparing the present methodology to ventilated capsules it is important to note the aspect of continuity of the measurement. Where the capsules can be left on the skin and provide a continuous trace of local sweating, the absorbents require a period between application to avoid an impact of the lack of evaporation from the local area in the sampling period on local sweating. Hence while absorbents provide information on large surface areas per sample, they can only provide a limited number of data points per zone per experiment.

Any measurement technique described so far in literature will affect the amount of sweat produced, though not all effects are immediately evident. For ventilated capsules, skin remains dry, which avoids hidromeiosis and thus may lead to higher sweat rates (Candas et al. 1980, 1983, Nadel and Stolwijk 1973). Also, the increased air speed over the skin was shown 
1 to increase sweat production at equal core temperature (Nadel and Stolwijk, 1973). On the other hand the increased evaporation may cool local skin and thus reduce sweat rate (Van Beaumont and Bullard 1965; Ogawa et al. 1986). For some absorbents techniques, the expectation is that the increasing wettedness of the absorbent patch may reduce sweating if not replaced regularly (Inoue et al. 1999), while the lack of evaporation will increase the skin temperature and thereby increases sweat production (Havenith 1991). For the present study a technical absorbent was chosen that could absorb without dripping a multiple (>40 times) of the amount actually absorbed in the testing, so relative moisture content remained low. Verde et al. (1982) ,using normal absorbents, have demonstrated that this method does not reduce the sweat rate of the covered area. The other effect, the increase in skin temperature, cannot be avoided however. In the current study this effect was alleviated by having short sample periods (5 minutes) and it was assumed that with all relevant skin areas covered at the same time, that though absolute sweating may increase slightly, the regional distribution should remain the same. Further, Cotter et al. (1995) discuss how their observed sweat distribution was only for $2.5 \%$ explained by the local skin temperature distribution, while Park and Tamura (1992) and Bothorel et al. (1991) observe dissociation between local sweat rate and temperature for rest and exercise respectively, indicating that the local skin temperature effect may be less at the higher skin temperature observed here, especially as the exercise intensity may be a bigger driver in the present experiment than the climate (Kondo et al. 2000). The effect of the coverage on total body temperature was kept small by covering less than $35 \%$ of the body, by keeping the coverage short, and by using a climate that allowed ample heat loss from uncovered areas.

With the present technique, absorbent patches are pressed against the skin using a stretch garment worn on top, causing light pressure on the skin. This may result in pressure-related changes in sweat rate, similar to the effect of hemi-hidrosis described by Kuno (1956). Ferres (1960) however demonstrated that the sweating in the pressure area was not reduced, but rather increased in the non pressure area. Further she showed no effect at all to occur with pressures up to $0.13 \mathrm{~N} / \mathrm{cm}^{2}$ (estimated from method details) caused by a $5 \mathrm{~kg}$ weight pressing against the side of the chest, which is magnitudes higher than that caused by the stretch textile in the present test which produces a rather uniform, low pressure. 
1 Summarising, the regional sweat rate data give a consistent picture, matching overall sweat 2 rates well. The regional distribution differs slightly between sexes for this group of equally fit male and female runners, though overall sweat rates do not. Sweating in both sexes is highest on the spine and lowest towards the periphery. The back as a whole sweats substantially more than the chest as a whole. Males had greater difference between the highest and lowest sweat areas than the females. Given the larger subject sample compared to other studies and the apparent general consistency with literature data the results are deemed to give a representative picture for this participant group in a 60 minute run. The present paper, together with other recent studies providing detailed data on the body's regional sweat distribution (Fogarty et al. 2007, feet; Machado-Moreira et al. 2007 $7^{\text {a.b }}$, head and torso; Smith et al. 2007, hands and arms; Taylor et al. 2006, feet), provides strong evidence for the dramatic variation of sweat rates over the body over short distances. This has important implications for the choice of location of sweat sampling equipment for thermoregulatory studies, for the representativeness of thermal models when regional effects are studied, for the development of sweating thermal manikins, and finally for the design of clothing. 


\section{References}

American College of Sports Medicine (2005) ACSM's guidelines for exercise testing and prescription. Williams and Wilkins, Baltimore.

Bar-or O (1998) Effects of age and gender on sweating pattern during exercise. Int J Sports Med 19 (Suppl) pS106-S107.

Bender R, Lange S (1998) What's wrong with arguments against multiplicity adjustments http://www.bmj.com/cgi/eletters/316/7139/1236.

Bittel J, Henane R (1975) Comparison of thermal exchanges in men and women under neutral and hot conditions. J. Physiol. (London), 250, 475-489.

Bothorel B, Dewasmes G, Hoeft A, Candas V (1991) Temperature and sweating responses in one-legged and two-legged exercise. Eur J Appl Physiol 63:157-164

Boysen TC, Yanagawa S, Sato F and Sato K. (1984) A modified anaerobic method of sweat collection. J Appl Physiol. 56(5) 1302-1307.

Candas V, Libert JP and Vogt JJ (1980) Effect of hidromeiosis on sweat drippage during acclimation to humid heat. Eur J Appl Physiol 44 123-33

Candas V, Libert JP, Vogt JJ (1983) Sweating and sweat decline of resting men in hot humid environments. Eur J Appl Physiol 50:223-234

Cotter JD, Patterson MJ, Taylor NAS (1995) The Topography Of Eccrine Sweating In Humans During Exercise. Eur J Appl Physiol 71 (6): 549-554.

Cunningham DJ, Stolwijk JAJ, Wenger CB (1978) Comparative thermoregulatory responses of resting men and women. J Appl Physiol 45(6), 908-915.

Davies CTM (1979) Thermoregulation during exercise in relation to sex and age. Eur J Appl Physiol, 42, 71-79.

Epstein Y, Stroschein AL, Pandolf KB (1987) Predicting Metabolic Cost Of Running With And Without Backpack Loads. Eur J Appl Physiol 56:495-500

Ferres HM (1960) The effect of pressure on sweating. J Physiol 151:591-597

Fogarty AL, Bartlett R, Ventenat V, Havenith G (2007) regional foot sweat rates during a 65minute uphill walk with a backpack. In: Mekjavic, I.B., Kounalakis, S.N., and Taylor, N.A.S. (Editors). Environmental Ergonomics XII. Biomed d.o.o., Ljubljana, Slovenia. ISBN 978-961-90545-1-2.

Folk GE, Semken A (1991) The evolution of sweat glands. Int J of Biomet, 35(3).

Fox RH, Löfstedt BE, Woodward PM, Eriksson E and Werkstrom B (1969) Comparison of thermoregulatory function in men and women. J Appl Physiol 196926 (4) 444-53. 
1 Haslag WM, Hertzman AB (1965) Temperature regulation of young women. J. Appl. Physiol., 20(6), 1283-1288.

Havenith G, van Middendorp H (1990) The relative influence of physical fitness, acclimation state, anthropometric measures and sex on individual reactions to heat stress. Eur J Appl Physiol 61:419-427

Havenith G, Luttikholt VGM, Vrijkotte TGM (1995) The relative influence of body characteristics on humid heat stress response. Eur J Appl Physiol 70:270-279

Havenith G (2001) An individual model of human thermoregulation for the simulation of heat stress response. J Appl Physiol 90: 1943-1954.

Havenith, G., Fogarty, A., Bartlett, R., Smith, C., and Ventenat, V. (2007). Upper body sweat distribution during and after a 60 minute training run in male and female runners. In: Mekjavic, I.B., Kounalakis, S.N., and Taylor, N.A.S. (Editors). Environmental Ergonomics XII. Biomed d.o.o., Ljubljana, Slovenia. ISBN 978-961-90545-1-2. Pp. 270-271.

Hertzman AB (1957) Individual differences in regional sweating. J Appl Physiol 10:242-248

Inoue Y, Nakao M, Araki T, Murakami H (1991) Regional differences in the sweating responses of older and younger men. J Appl Physiol 71:2453-2459

Inoue Y, Havenith G, Kenney WL, Loomis JL, Buskirk ER (1999) Exercise- and methylcholine-induced sweating responses in older and younger men: effect of heat acclimation and aerobic fitness. Int J Biomet 42(4) 210-216.

Inoue Y, Tanaka Y, Omori K, Kuwahara T, Ogura Y, Ueda H (2005) Sex- and menstrual cycle-related differences in sweating and cutaneous blood flow in response to passive heat exposure. Eur J Appl Physiol 94:323 -332.

ISO 9920 (2007) Ergonomics of the thermal environment. Estimation of the thermal insulation and evaporative resistance of a clothing ensemble, International Standardisation Organisation, Geneva, 2003.

Jablonski NG (2006) Skin, A Natural History. Univ Press California, Columbia And Princeton (United States), ISBN: 9780520242814.

Kawahata A (1960) Sex differences in sweating. Essential Problems in climatic physiology (Ito, S., et al. (eds)). Nankodo Publisher, Kyoto, pp169-184.

Kenney WL (1985) A review of comparative responses of men and women to heat stress Environmental research 37:1-11.

Knip A (1969) Measurement and regional distribution of functioning eccrine sweat glands in male and female Caucasians. Human Biology 41 (3) 380-387. 
1 Kenney WL, Fowler SR (1988) Methylcholine-activated eccrine sweat gland density and output as a function of age. J Appl Physiol 65 (3) 1082-1086.

Kondo N, Takano S, Aoki K, Shibasaki M, Tominaga H and Inoue Y (1998) Regional differences in the effect of exercise intensity on thermoregulatory sweating and cutaneous vasodilation. Acta Physiol Scand 164 71-78.

Kondo N, Tominaga H, Shibasaki M (2000) Effects of exercise intensity on the sweating response to a sustained static exercise. J Appl Physiol 88 (5): 1590-1596

Kuno Y (1956) Human Perspiration. Charles C Thomas Publ. Springfield, Ill.

Machado-Moreira, C.A., Smith, F.M., van den Heuvel, A.M.J., Mekjavic, I.B., and Taylor, N.A.S. $\left(2007^{\mathrm{a}}\right)$. Sweat secretion from the torso during passively-induce and exerciserelated hyperthermia. Eur. J. Appl. Physiol. (This issue)

Machado-Moreira, C.A., Wilmink, F., Meijer, A., Mekjavic, I.B., and Taylor, N.A.S. (2007 $\left.{ }^{\mathrm{b}}\right)$. Local differences in sweat secretion from the head during rest and exercise in the heat. Eur. J. Appl. Physiol. (This issue)

Nadel ER, Bullard RW, Stolwijk JAJ (1971) Importance of skin temperature in the regulation of sweating. J Appl Physiol 31(1):80-87

Nadel ER, and Stolwijk JAJ (1973) Effect of skin wettedness on sweat gland response. J Appl Physiol 35 (5): 689-694

Ogawa T, Asayama M (1986) Quantitative analysis of the local effect of skin temperature on sweating. Jpn J Physiol 36:417422

Park SA, Tamura T (1992) Distribution of evaporation rate on human body surface. Ann Physiol Anthropol 11:593-609

Perneger TV (1998) What's wrong with Bonferroni adjustments, BMJ 316:1236-1238.

Randall WC (1946) Quantitation and regional distribution of sweat glands in man. J Clin Invest 25:761-767

Smith C, Ventenat V, Havenith G. (2007) Regional sweat rates of the arms and hands in male squash players. In: Mekjavic, I.B., Kounalakis, S.N., and Taylor, N.A.S. (Editors). Environmental Ergonomics XII. Biomed d.o.o., Ljubljana, Slovenia. ISBN 978-961-90545$1-2$.

Sodeman WA, Burch GE (1944) Regional variations in water loss from the skin of diseased subjects living in a subtropical climate. J Clin Invest 23(1): 37-43 
1 Taylor NAS, Caldwell JN, Mekjavic IB (2006) The sweating foot: Local differences in sweat secretion during exercise-induced hyperthermia. Aviat Space Environm Med 77 (10): $3 \quad 1020-1027$

4 Van Beaumont W, Bullard RW (1965) Sweating: direct influence of skin temperature. $5 \quad$ Science $147: 1465-1467$

6 Verde T, Shephard RJ, Corey P, Moore R (1982) Sweat composition in exercise and in heat. J Appl Physiol. 53(6):1540-1545

8 Weiner JS (1945) The regional distribution of sweating. J Physiol 104:32-40.

9 Wyndham CH, Morrison JF and Williams CG (1965) Heat reactions of male and female Caucasians. J Appl Physiol, 20(3), 357-364. 
2 Table 1, participant characteristics $( \pm \mathrm{SD})$, overall sweat data and heart rates (HR) during the run. * denotes significant difference males

3 versus females at $\mathbf{p}<\mathbf{0 . 0 5}$.

\begin{tabular}{|c|c|c|c|c|c|c|c|c|c|c|}
\hline & $\begin{array}{c}\text { age } \\
\text { (years) }\end{array}$ & $\begin{array}{c}\text { height } \\
\text { (m) }\end{array}$ & $\begin{array}{c}\text { weight } \\
\text { (kg) }\end{array}$ & $\begin{array}{c}\text { surface } \\
\text { area } \\
\left(\mathbf{m}^{2}\right)\end{array}$ & $\begin{array}{c}\dot{V} O_{2 \max } \\
\left(\mathbf{m l} \cdot \mathbf{k g}^{\mathbf{1}} \cdot \mathbf{m i n}^{-\mathbf{1}}\right)\end{array}$ & $\begin{array}{l}\text { sweat loss based } \\
\text { on whole body } \\
\text { mass loss } \\
\text { (g) }\end{array}$ & $\begin{array}{l}\text { sweat loss based } \\
\text { on whole body } \\
\text { mass loss } \\
\left(\mathrm{g} \cdot \mathrm{m}^{-2} \cdot \mathrm{h}^{-1}\right)\end{array}$ & $\begin{array}{l}\text { HR at } \\
25 \mathrm{~min}\end{array}$ & $\begin{array}{l}\text { HR at } \\
55 \mathrm{~min}\end{array}$ & $\begin{array}{c}\text { treadmill } \\
\text { speed } \\
\left(\mathbf{k m} \cdot \mathbf{h}^{-1}\right)\end{array}$ \\
\hline Female & $27.6 \pm 5.6$ & $1.69 \pm 0.04 *$ & $64.3 \pm 5.9 *$ & $1.74 \pm 0.09^{*}$ & $55.3 \pm 6.2$ & $975 \pm 300$ & $420 \pm 114$ & $167 \pm 13$ & $156 \pm 11$ & $10.8 \pm 1.2$ \\
\hline Male & $28.4 \pm 7.7$ & $1.75 \pm 0.1$ & $72.9 \pm 6.5$ & $1.88 \pm 0.1$ & $52.3 \pm 4.4$ & $1171 \pm 103$ & $474 \pm 80$ & $155 \pm 9$ & $157 \pm 10$ & $10.2 \pm 1.3$ \\
\hline
\end{tabular}


1 Table 2, Regional exercise period sweat rate data over all sampled areas. For conversion to other units: divide by 600 to get $\mathrm{mg}^{-\mathrm{cm}^{-2}} . \mathrm{min}^{-1}$, or by 210000 to get $\mathbf{m l} . \mathrm{cm}^{-2} \cdot \mathrm{h}^{-1}$ Significance levels: numbers are given for $0.1<\mathbf{p} \leq 0.5$; *:p $<0.05$; **: $\mathbf{p}<0.01$; ***:p $<0.001$; \#:p<0.05 after Bonferroni

3 correction; \$: $0.1<\boldsymbol{p} \leq \mathbf{0 . 0 5}$ after Bonferroni correction).

\begin{tabular}{|c|c|c|c|c|c|c|c|c|c|c|c|c|}
\hline \multirow{3}{*}{ sex: } & \multicolumn{10}{|c|}{ absolute data $\left(\mathrm{g} \cdot \mathrm{m}^{-2} \cdot \mathrm{h}^{-1}\right)$} & \multirow{2}{*}{\multicolumn{2}{|c|}{$\begin{array}{l}\text { significance level of male-female comparison } \\
\text { (post-hoc analysis of zone-sex interaction) }\end{array}$}} \\
\hline & \multicolumn{5}{|c|}{ female } & \multicolumn{5}{|c|}{ male } & & \\
\hline & $\min$ & $\max$ & median & mean & $\mathrm{sd}$ & $\min$ & $\max$ & $\begin{array}{c}\text { media } \\
\mathrm{n}\end{array}$ & mean & sd & absolute data (fig 2) & $\begin{array}{l}\text { normalised ratio data (fig } \\
\text { 3) }\end{array}$ \\
\hline left scapula & 240 & 1195 & 520 & 606 & 305 & 361 & 1110 & 783 & 764 & 213 & - & - \\
\hline right scapula & 349 & 1221 & 459 & 651 & 298 & 442 & 1023 & 706 & 725 & 174 & - & - \\
\hline scapulas & 295 & 1208 & 485 & 629 & 298 & 402 & 1067 & 744 & 745 & 190 & - & - \\
\hline top central back & 411 & 1852 & 843 & 953 & 485 & 478 & 1208 & 800 & 796 & 224 & - & * \\
\hline mid central back & 356 & 1800 & 762 & 882 & 445 & 540 & 1491 & 1053 & 1024 & 287 & - & - \\
\hline mean central back & 383 & 1556 & 888 & 917 & 402 & 509 & 1246 & 934 & 910 & 211 & - & - \\
\hline left mid back & 243 & 584 & 463 & 449 & 96 & 413 & 2039 & 803 & 920 & 459 & $* *$ & *** \# \\
\hline right mid back & 211 & 521 & 427 & 405 & 94 & 362 & 1080 & 890 & 770 & 269 & *** \# & $* * \$$ \\
\hline mean mid lateral back & 306 & 535 & 445 & 427 & 77 & 387 & 1517 & 797 & 845 & 326 & $* *$ & *** \# \\
\hline left lower back & 389 & 1068 & 549 & 628 & 223 & 318 & 1822 & 516 & 691 & 453 & - & - \\
\hline right lower back & 393 & 1058 & 573 & 663 & 217 & 236 & 1240 & 584 & 618 & 304 & - & * \\
\hline mean lower lateral back & 411 & 952 & 604 & 645 & 182 & 308 & 1531 & 594 & 654 & 357 & - & - \\
\hline lower back & 240 & 1158 & 420 & 537 & 286 & 281 & 1307 & 720 & 732 & 326 & - & - \\
\hline top front & 279 & 1686 & 573 & 745 & 428 & 228 & 799 & 588 & 564 & 178 & - & $* *$ \\
\hline mid front & 157 & 1129 & 397 & 475 & 287 & 391 & 1140 & 618 & 715 & 248 & $*$ & .09 \\
\hline lower front & 240 & 727 & 346 & 424 & 169 & 311 & 682 & 472 & 499 & 120 & - & - \\
\hline sides & 131 & 523 & 300 & 318 & 109 & 255 & 802 & 428 & 449 & 160 & * & $*$ \\
\hline arms & 215 & 622 & 258 & 333 & 134 & 111 & 411 & 213 & 245 & 112 & - & *** \# \\
\hline shoulders & 291 & 820 & 347 & 471 & 214 & 231 & 795 & 583 & 540 & 187 & - & - \\
\hline $\begin{array}{l}\text { overall area weighted } \\
\text { mean of sampled zones } \\
\text { during exercise }\end{array}$ & 288 & 976 & 507 & 565 & 222 & 339 & 875 & 603 & 636 & 165 & - & - \\
\hline $\begin{array}{l}\text { Whole body sweat rate } \\
\text { over whole experimental } \\
\text { period }\end{array}$ & 288 & 615 & 372 & 420 & 114 & 377 & 598 & 460 & 474 & 80 & - & - \\
\hline
\end{tabular}




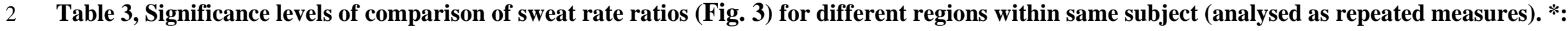
$3 \mathbf{p}<\mathbf{0 . 0 5} ; * *: \mathbf{p}<\mathbf{0 . 0 1} ; * * *$ : $\mathbf{p} \leq \mathbf{0 . 0 0 1}$; \#:p<0.05 after Bonferroni correction; $\$ \mathbf{~} 0.1<\mathbf{p} \leq \mathbf{0 . 0 5}$ after Bonferroni correction).

\begin{tabular}{|c|c|c|c|c|c|c|c|c|c|c|}
\hline & Scapula & $\begin{array}{l}\text { Central } \\
\text { back }\end{array}$ & $\begin{array}{l}\text { Side } \\
\text { mid } \\
\text { back }\end{array}$ & $\begin{array}{l}\text { Side } \\
\text { lower } \\
\text { back }\end{array}$ & $\begin{array}{l}\text { Lower } \\
\text { back }\end{array}$ & $\begin{array}{l}\text { Top } \\
\text { front }\end{array}$ & $\begin{array}{l}\text { Mid } \\
\text { front }\end{array}$ & $\begin{array}{l}\text { Lower } \\
\text { front }\end{array}$ & side & arm \\
\hline Central back & $\star \star \star \#$ & & & & & & & & & \\
\hline Side mid back & - & $\star \star * * \#$ & & & & & & & & \\
\hline Side lower back & - & $\star \star \star \#$ & - & & & & & & & \\
\hline Lower back & - & $\star \star \star \#$ & - & - & & & & & & \\
\hline Top front & - & $\star \star \star * \#$ & - & - & - & & & & & \\
\hline Mid front & - & $\star \star * *$ & - & - & - & - & & & & \\
\hline Lower front & $\star \star \star \#$ & $\star \star \star * \#$ & $\star \star \star * \#$ & $\star \star \star \star \$$ & * & $\star \star \star \#$ & * & & & \\
\hline Side & $\star \star \star \star ~ \#$ & $\star \star \star * \#$ & $\star \star \star * ~ \#$ & $\star \star \star \star ~ \# ~$ & *** \# & $\star \star \star * ~ \#$ & $\star \star \star \#$ & $\star \star \star \star ~ \# ~$ & & \\
\hline Arm & $\star \star \star * \#$ & $\star * \star \#$ & $* \star \star \#$ & $\star \star \star * \#$ & $\star \star * * \#$ & $\star * \star \#$ & $* \star * \#$ & $\star \star \star * \#$ & ** & \\
\hline shoulder & $\star \star \star \star ~ \#$ & $\star \star \star \#$ & $\star \star \star \$$ & $\star \star \star \$$ & * & ** & - & - & $\star \star \star \$$ & $\star \star \star \#$ \\
\hline
\end{tabular}


Fig. 1, schematic drawing of the test protocol. Before and after test participants were weighed. First 5 minutes used to bring heart rate in target range by changing treadmill speed. Sweat sampled from minute 33-38, 48-53 and 70-75. Minutes 60-75 were rest.

Fig. 2, Median regional sweat rate values for male and female runners, rounded to nearest $10 \mathrm{~g}$ and averaged over left and right symmetrical zones.

Fig. 3, Mean regional sweat rate values as ratios to surface weighted mean sweat rate of all measured zones for male and female runners, averaged over left and right symmetrical zones. 
1

2

3

4

5

6

7

8

9

10

11

12

13

14

15

Added references:

DOI: 10.1055/s-2007-971970

O. Bar-Or (1968) Effects of Age and Gender on Sweating Pattern During Exercise Int J Sports Med 1998; 19: S106-S107 